\title{
Validation of pre-operative risk scores of contrast-induced acute kidney injury in a Chinese cohort
}

Wenjun Yin ${ }^{1 \dagger}$, Ge Zhou ${ }^{1 \dagger}$, Lingyun Zhou', Mancang Liu', Yueliang Xie', Jianglin Wang ${ }^{1}$, Shanru Zuo', Kun Liu', Can $\mathrm{Hu}^{1}$, Linhua Chen ${ }^{1}$, Huiqin Yang ${ }^{1}$ and Xiaocong Zuo ${ }^{1,2^{*}}$ (D)

\begin{abstract}
Background: Pre-operative risk scores are more valuable than post-procedure risk scores because of lacking effective treatment for contrast-induced acute kidney injury (CI-AKI). A number of pre-operative risk scores have been developed, but due to lack of effective external validation, most of them are also difficult to apply accurately in clinical practice. It is necessary to review and validate the published pre-operative risk scores for Cl-AKI.

Materials and methods: We systematically searched PubMed and EMBASE databases for studies of Cl-AKI preoperative risk scores and assessed their calibration and discriminatory in a cohort of 2669 patients undergoing coronary angiography or percutaneous coronary intervention (PCI) from September 2007 to July 2017. The definitions of $\mathrm{Cl}$-AKI may affect the validation results, so three definition were included in this study, Cl-AKI broad1 was defined as an increase in serum creatinine (Scr) of $44.2 \mu \mathrm{mol} / \mathrm{L}$ or $25 \%$; Cl-AKI broad2, an increase in Scr of $44.2 \mu \mathrm{mol} / \mathrm{L}$ or $50 \%$; and Cl-AKI-narrow, an increase in Scr of $44.2 \mu \mathrm{mol} / \mathrm{L}$. The calibration of the model was assessed with the Hosmer-Lemeshow test and the discriminatory capacity was identified by C-statistic.

Results: Of the 8 pre-operative risk scores for $\mathrm{Cl}$-AKI identified, 7 were single-center study and only 1 was based on multi-center study. In addition, 7 of the scores were just validated internally and only Chen score was externally validated. In the validation cohort of 2669 patients, the incidence of $\mathrm{Cl}$-AKI ranged from 3.0\%(Liu) to 16.4\%(Chen) for these scores. Furthermore, the incidence of Cl-AKI was 6.59\% (178) for Cl-AKI broad1, 1.44\% (39) for Cl-AKI broad2, and $0.67 \%$ (18) for Cl-AKI-narrow. For Cl-AKI broads, C-statistics varied from 0.44 to 0.57 . For Cl-AKI-narrow, the Maioli score had the best discrimination and calibration, what's more, the C-statistics of Maioli, Chen, Liu and Ghani was $\geq 0.7$.

Conclusion: Most pre-operative risk scores were established based on single-center studies and most of them lacked external validation. For Cl-AKI broads, the prediction accuracy of all risk scores was low. The Maioli score had the best discrimination and calibration, when using the Cl-AKI-narrow definition.
\end{abstract}

Keywords: Risk scores, Contrast-induced acute kidney injury, Percutaneous coronary intervention, Coronary angiography, Contrast media

\footnotetext{
* Correspondence: zuoxc08@126.com

'Wenjun Yin and Ge Zhou contributed equally to this work.

'Department of Pharmacy, The Third Xiangya Hospital of Central South

University, Changsha, China

${ }^{2}$ Center of Clinical Pharmacology, The Third Xiangya Hospital of Central

South University, Changsha, China
}

(c) The Author(s). 2020 Open Access This article is distributed under the terms of the Creative Commons Attribution 4.0 International License (http://creativecommons.org/licenses/by/4.0/), which permits unrestricted use, distribution, and reproduction in any medium, provided you give appropriate credit to the original author(s) and the source, provide a link to the Creative Commons license, and indicate if changes were made. The Creative Commons Public Domain Dedication waiver (http://creativecommons.org/publicdomain/zero/1.0/) applies to the data made available in this article, unless otherwise stated. 


\section{Background}

Nowadays, iodinated contrast media (CM) have been widely used clinically to improve diagnosis and treatment, with more than 75 million CM used worldwide each year [1, 2]. Acute kidney injury is a common adverse reaction caused by $\mathrm{CM}$. Contrast-induced acute kidney injury (CI-AKI) has become the third prevalent cause of all hospital-acquired renal failure, accounting for $12 \%$ [3]. The incidence of CI-AKI was $11 \%$ in lowrisk population [4], 40\% in chronic renal insufficiency population [5] and 50\% in diabetic nephropathy population [6]. 18.6\% of CI-AKI patients suffered from persistent renal injury, the incidence of chronic kidney disease (CKD) and the total mortality caused by CI-AKI was $7 \% \sim 31 \%$, and the average hospitalization time and social-economic burden increased by $5 \sim 10$ times $[7,8]$. It can be seen that CI-AKI has become an obstacle to the clinical application of CM.

Unfortunately, so far no strategy has been proven to effectively cure CI-AKI $[9,10]$. Therefore, the risk scores for CI-AKI are critical to reduce the incidence of CIAKI. Risk scores can be used to identify high-risk patients who may benefit from preventive strategies such as hydration. Many risk scores for CI-AKI have been established, and the Mehran score, based on percutaneous coronary intervention (PCI) patients in the United States, has been the most classic predictive score and widely used all over the world [11]. However, in our previous study, the accuracy of Mehran score in Chinese patients was limited [12]. Due to population inconsistency, these scores may not be applicable to nondevelopment populations who weren't included in the derivation cohort.

Many risk scores included operational variables, such as contrast volume, which are usually not known until the procedure is executed. Thus, these scores can only be used after the operation is completed. However, postoperative predictions do not make much sense because only pre-operative prevention measures can reduce the risk of CI-AKI for no treatment strategy. Pre-operative risk scores are more feasible in clinical applications and have been increasingly established. However, most of these pre-operative risk scores lacked effective external validation and are therefore difficult to apply accurately to clinical practice. In this study, our goal was to review and validate the published pre-operative risk scores for $\mathrm{CI}-\mathrm{AKI}$ and to provide a reference for clinical use of CIAKI risk scores.

\section{Methods}

\section{Data sources and searches}

We systematically searched the PubMed (1950 to April 2019) and EMBASE (1980 to April 2019) databases for the studies of CI-AKI risk scores. References to all identified articles and previous systematic reviews were also scanned for potential search criteria. The search strategy was provided in detail in Additional file 1: Table S1. Two researchers independently evaluated all design types and screened for all risk scores for predicting CIAKI. We limited inclusion to studies published in English.

\section{Study population}

A retrospective cohort study was conducted among patients to whom CM was administered for coronary angiography or PCI at the Third Xiangya Hospital of Central South University from October 2007 to July 2017. Nine thousand thirteen patients were identified by the electronic medical record system at the Third Xiangya Hospital of Central South University, Changsha, China. Patients without left ventricular ejection fraction $(n=$ 3512), and without baseline Scr and a second Scr within $72 \mathrm{~h}$ after procedure $(n=2832)$ were excluded, because without baseline Scr and changed Scr after angiography, CI-AKI could not be determined.

Detailed demographic and clinical characteristics were collected from the structured hospital information system (HIS) including demographics, left ventricular ejection fraction, baseline serum creatinine (Scr) value, high-density lipoprotein, one procedure effected within the past $72 \mathrm{~h}$, urgent $\mathrm{PCI}$, myocardial infarction, diabetes, hypotension, anemia, congestive heart failure, shock, multivessel PCI, previous percutaneous coronary intervention, and acute coronary syndrome. In addition, in order to ensure the accuracy of model verification, all variables were consistent with original studies of the risk scores as much as possible. MDRD formula was used in Chen score and Cockroft and Gault formula was used in Maioli and Lian scores. Thus, in this study the creatinine clearance $(\mathrm{CrCl})$ was calculated by the Cockcroft-Gault (C-G) equation in Maioli score and Lian score: [(140age) $\times$ weight $(\mathrm{kg})] /[72 \times \mathrm{Scr}(\mathrm{mg} / \mathrm{dL})] \times 0.85$ (for female) [13], and the estimated glomerular filtration rate (eGFR) was calculated by the Modification of Diet in Renal Disease equation (MDRD) in Chen score: $[186 \times \mathrm{Scr}$ $(\mathrm{mg} / \mathrm{dl})-1.154] \times$ age-0.203 $\times 0.742$ (if female) [14]

\section{Definition}

The primary study end point was the incidence of CIAKI. At present, the definition of CI-AKI has not been unified, the most commonly used clinical definition comes from the Contrast Media Safety Committee (CMSC) of the European Society of Urogenital Radiology (ESUR), in which renal function has a worsening (Scr increases by more than $25 \%$ or $44.2 \mu \mathrm{mol} / \mathrm{L}$ ) within 3 days after intravascular administration of $\mathrm{CM}$ in the absence of a surrogate cause [15]. However, the relative increase in $\mathrm{Scr}$ was found to overestimate CI-AKI with normal 
renal function, and absolute values were considered to be preferred [16], and many studies used the definition of an increase in Scr of $44.2 \mu \mathrm{mol} / \mathrm{L}$ only, or increase 25 to $50 \%$. The definitions may affect the validation results, so three definition were included in this study: CI-AKI broad1, CI-AKI broad2 and CI-AKI narrow. CI-AKI broad1 was defined as an increase in Scr of $44.2 \mu \mathrm{mol} / \mathrm{L}$ or $25 \%$ relative increase in Scr, CI-AKI broad2 was defined as an increase in Scr of $44.2 \mu \mathrm{mol} / \mathrm{L}$ or $50 \%$ relative increase in Scr, and CI-AKI-narrow was defined an increase in Scr of $44.2 \mu \mathrm{mol} / \mathrm{L}$. The earliest Scr concentration within 14 days prior to surgery was defined as baseline Scr, and the highest Scr within $72 \mathrm{~h}$ after surgery was used as the follow-up Scr to evaluate the incidence of CI-AKI.

Anemia was defined as a baseline hematocrit value of $\leq 39 \%$ for men and $\leq 36 \%$ for women, which were consistent with original studies of Chen score. Hypotension was defined as a systolic blood pressure $\leq 90 \mathrm{mmHg}$ for at least $1 \mathrm{~h}$. Congestive heart failure (CHF) was defined as functional class III or IV of the New York Heart Association. Urgent PCI was defined as the procedure that was implemented within $12 \mathrm{~h}$ of admission.

\section{Statistical analysis}

To compare the differences between the different scores, all patients were divided into low-, moderate- and highrisk groups based on the risk scores calculated from patient demographic and clinical characteristics (Table 1). In the studies by Maioli, Chen and Ghani score, patients were divided into four groups: low- risk, moderate- risk, high- risk and very high-risk groups. We classified highrisk and very high-risk groups into the high-risk group in our study. For the Inohara score, the total score $\leq 0$, $1 \leq$ total scores $\leq 10$, and high total score $\geq 11$ were defined as the low-, moderate-, and high-risk groups in this study, respectively.

IBM SPSS Version 22.0 (SPSS, Inc., Chicago, IL) and R (version2.12.0) were used for all analyses. Continuous variables were expressed as mean and standard deviation (SD). The t-test was used to compare the continuous variables of the normal distribution; otherwise, the Mann-Whiney U-test was performed. The categorical variables were performed by chi-square test. Discrimination and calibration were used to assess score performances. Discrimination is a measure of the ability to distinguish between patients who will and will not develop CI-AKI, as determined by $\mathrm{C}$-statistic, which is tested using the area under the receiver operating characteristic curve [17]. The score was considered to have acceptable discriminating power with a C-statistic $>0.70$. Calibration, which measures whether the predicted value of the model is consistent with the probability of occurrence of the final event, as the evaluated by Hosmer-
Lemeshow test. All statistical tests were two-tailed, and accepted statistical significance at $P<0.05$.

\section{Results \\ Overview of risk scores}

Our search strategy yielded 20,361 citations through the PubMed database and 1871 citations through the EMBASE database (Fig. 1). We excluded citations based on screening headlines and abstracts mainly due to nonCI-AKI or acute kidney injury outcomes, non-risk scores or prediction models, animal studies and irrelevant to our goals, leaving 71 full-text articles eligible for evaluation. We subsequently excluded 51 studies with no relevant risk scores for predicting CI-AKI $(n=15)$, reviews and letters to the editor $(n=8)$, only for validating risk scores $(n=10)$, the model in which was not converted to a score $(n=1)$, the scores in which for the risk of CI-AKI was not assessed $(n=16)$, and not an English article $(n=1)$. This produced 20 research risk scores for CI-AKI. In addition, we excluded 11 post-procedure risk scores for CI-AKI according to our goals [18-28], and due to lack of $\mathrm{C}$-reactive protein data, the Athens score was excluded [29]. We ultimately included 8 preoperative risk scores for CI-AKI in the final validation analysis [30-37].

All studies included patients who underwent coronary angiography or PCI (Table 2), all of whom suffered from diabetes in the Zeng score and the age of patients in the Lian score $>65$ years. Only one score (Inohara) was developed in the multi-center. The Inohara score included the largest number of developing patients who were included in the derivation cohort $(n=3975)$ and Ghani had the least $(n=247)$. The incidence of CI-AKI ranged from $3.0 \%(\mathrm{Liu})$ to $16.4 \%(\mathrm{Chen})$. In addition, the definitions of CI-AKI in the original studies of pre-operative risk scores were defined differently (Table 3), largely because of varying onset time and changes in Scr. Some of pre-operative risk scores defined CI-AKI at $48 \mathrm{~h}, 72 \mathrm{~h}$, $48-72 \mathrm{~h}$ or 5 days of onset, and 5 of them used only an absolute Scr increasing by $44.2 \mu \mathrm{mol} / \mathrm{L}$ but no relative increase. All scores were validated internally by using sliding samples, but only Chen score was validated externally by one cohort from Guangdong General Hospital [38]. Of the 8 scores, 2 had good discrimination in the development cohort and 5 in the validation cohort $(\mathrm{C}$ statistic >0.8). The most common risk factors for the score included baseline $\mathrm{Scr}$ or eGFR or $\mathrm{CrCl}$ (eGFR) value (all scores), old age (7 scores), and diabetes (5 scores).

\section{Baseline characteristics and risk of $\mathrm{Cl}-\mathrm{AKI}$}

Of a total of 9013 coronary angiography and PCI patients, 2669 patients were included in the study, and the excluded numbers were showed in Additional file 1: 
Table 1 Variables in risk scores evaluated

\begin{tabular}{|c|c|c|c|c|c|}
\hline \multirow[t]{2}{*}{ Scores } & \multirow[t]{2}{*}{ Variables } & \multirow[t]{2}{*}{ Score } & \multicolumn{3}{|l|}{ Groups } \\
\hline & & & Low-risk & Moderate-risk & High-risk \\
\hline \multirow[t]{7}{*}{ Maioli Score } & Age $\geq 73$ years & 1 & score $\leq 3$ & score 4-6 & score $\geq 7$ \\
\hline & Diabetes & 2 & & & \\
\hline & Left ventricular ejection fraction $\leq 45 \%$ & 2 & & & \\
\hline & Baseline serum creatinine value $\geq 1.5 \mathrm{mg} / \mathrm{dL}$ & 2 & & & \\
\hline & Creatinine clearance $\leq 44 \mathrm{~mL} / \mathrm{min}$ & 2 & & & \\
\hline & Pre-procedure creatinine $\geq$ baseline creatinine & 2 & & & \\
\hline & One procedure effected within the past $72 \mathrm{~h}$ & 3 & & & \\
\hline \multirow[t]{9}{*}{ Chen Score } & Age $\geq 70$ years & 4 & score $\leq 7$ & score $8-12$ & score $\geq 13$ \\
\hline & History of myocardial infarction & 5 & & & \\
\hline & Diabetes & 4 & & & \\
\hline & Hypotension & 6 & & & \\
\hline & Left ventricular ejection fraction $\leq 45 \%$ & 4 & & & \\
\hline & Anemia & 3 & & & \\
\hline & Estimated glomerular filtration rate $<60\left(\mathrm{~mL} / \mathrm{min} / 1.73 \mathrm{~m}^{2}\right)$ & 7 & & & \\
\hline & High-density lipoprotein < 1 mmol/L & 3 & & & \\
\hline & Urgent $\mathrm{PCl}^{\mathrm{a}}$ & 3 & & & \\
\hline \multirow[t]{3}{*}{ Liu Score } & Age $\geq 75$ years & 1 & score $=0$ & score $=1$ & score $\geq 2$ \\
\hline & Left ventricular ejection fraction $<40 \%$ & 1 & & & \\
\hline & Serum creatinine $>1.5 \mathrm{mg} / \mathrm{dL}$ & 2 & & & \\
\hline \multirow[t]{3}{*}{ Lian Score } & Age $>75$ years & 1.5 & score $\leq 1$ & score 1-3 & score $\geq 3$ \\
\hline & Creatinine clearance $<60 \mathrm{~mL} /$ minute & 1 & & & \\
\hline & Congestive heart failure & 1.5 & & & \\
\hline \multirow[t]{4}{*}{ Lin Score } & Age $>75$ years & 1 & score $<1$ & score $1-2$ & score $\geq 3$ \\
\hline & Hypotension & 1 & & & \\
\hline & Use of intra-aortic balloon pump & 1 & & & \\
\hline & Serum creatinine $>1.5 \mathrm{mg} / \mathrm{dL}$ & 1 & & & \\
\hline \multirow[t]{5}{*}{ Ghani Score } & Basal creatinine $>115 \mu \mathrm{mol} / \mathrm{L}$ & 7 & score $\leq 4$ & score $5-8$ & score $\geq 9$ \\
\hline & Shock & 3 & & & \\
\hline & Female gender & 2 & & & \\
\hline & Multivessel $\mathrm{PCl}^{\mathrm{a}}$ & 2 & & & \\
\hline & Diabetes & 2 & & & \\
\hline \multirow[t]{12}{*}{ Inohara Score } & Age & & score $\leq 0$ & score $1-10$ & score $\geq 11$ \\
\hline & $\leq 50$ & 0 & & & \\
\hline & $51-59$ & 1 & & & \\
\hline & $60-69$ & 2 & & & \\
\hline & $70-79$ & 3 & & & \\
\hline & $80-89$ & 4 & & & \\
\hline & $90-99$ & 5 & & & \\
\hline & Heart failure status & 3 & & & \\
\hline & Diabetes & 2 & & & \\
\hline & Previous percutaneous coronary intervention & -3 & & & \\
\hline & Hypertension & 2 & & & \\
\hline & Pre-creatinine> $1.0 \mathrm{mg} / \mathrm{dL}$ & 4 & & & \\
\hline
\end{tabular}


Table 1 Variables in risk scores evaluated (Continued)

\begin{tabular}{llllll}
\hline Scores & Variables & Score & & Groups & \\
\cline { 5 - 5 } & & & Low-risk & Moderate-risk & High-risk \\
\hline \multirow{3}{*}{ Zeng Score } & Acute coronary syndrome & 5 & & & \\
& Age $\geq 75$ years & 1 & score $\leq 1$ & score $2-4$ & \\
& Acute myocardial infarction & 1 & & \\
& Serum creatinine $>1.5 \mathrm{mg} / \mathrm{dL}$ & 2 & & \\
& IABP & & 2 & \\
\end{tabular}

${ }^{\mathrm{a}} \mathrm{PCI}$ Percutaneous coronary intervention; ${ }^{\mathrm{b}} / A B P$ intra-aortic balloon pump

Figure S1. Their demographic, laboratory and procedural characteristics were seen in Table 4 and Additional file 2. Among them, the mean age was $63.31( \pm 10.21)$ years, females were $34.75 \%$, and the prevalence of diabetes and hypertension were 39.15 and $54.96 \%$, respectively. The incidence of CI-AKI was 6.59\% (178/2699) for CI-AKI broad1, $1.44 \%(39 / 2699)$ for CI-AKI broad2 and $0.67 \%$ (18/2699) for CI-AKI-narrow, respectively. Patients with CI-AKI broad1 had a higher prevalence of female, hypotension and anemia. The average age of patients in CI-AKI-narrow cohort was higher. Both eGFR and $\mathrm{CrCl}$ were significantly higher in the CI-AKI broads and narrow groups compared to the non-CI-AKI groups.

\section{Distribution of patients in the different risk categories}

All patients were divided into low-, moderate-, and high-risk groups (Fig. 2). When the definition of CI-AKI broad1 was used, the incidence in the low-risk group was not significantly lower than that in the moderaterisk and high-risk groups, and the high-risk group was lower than the moderate-risk group, except for Chen and Ghani. There were no CI-AKI patients in the highrisk group of Lin and Zeng. Lin and Ghani had the highest incidence in low-risk groups. Liu and Lian had the highest incidence in high-risk groups if the broad 2 definition was used, and no CI-AKI patients were found in the high-risk groups of Lin and Zeng and the low-risk group of Inohara. For the Chen, Liu, Lian, and Inohara scores, the incidence of CI-AKI increased with increasing risk when using the CI-AKI-narrow definition.

\section{Calibration and discrimination}

The best calibration was observed for the Maioli score, and the Liu, Lian, Lin, and Inohara scores showed good

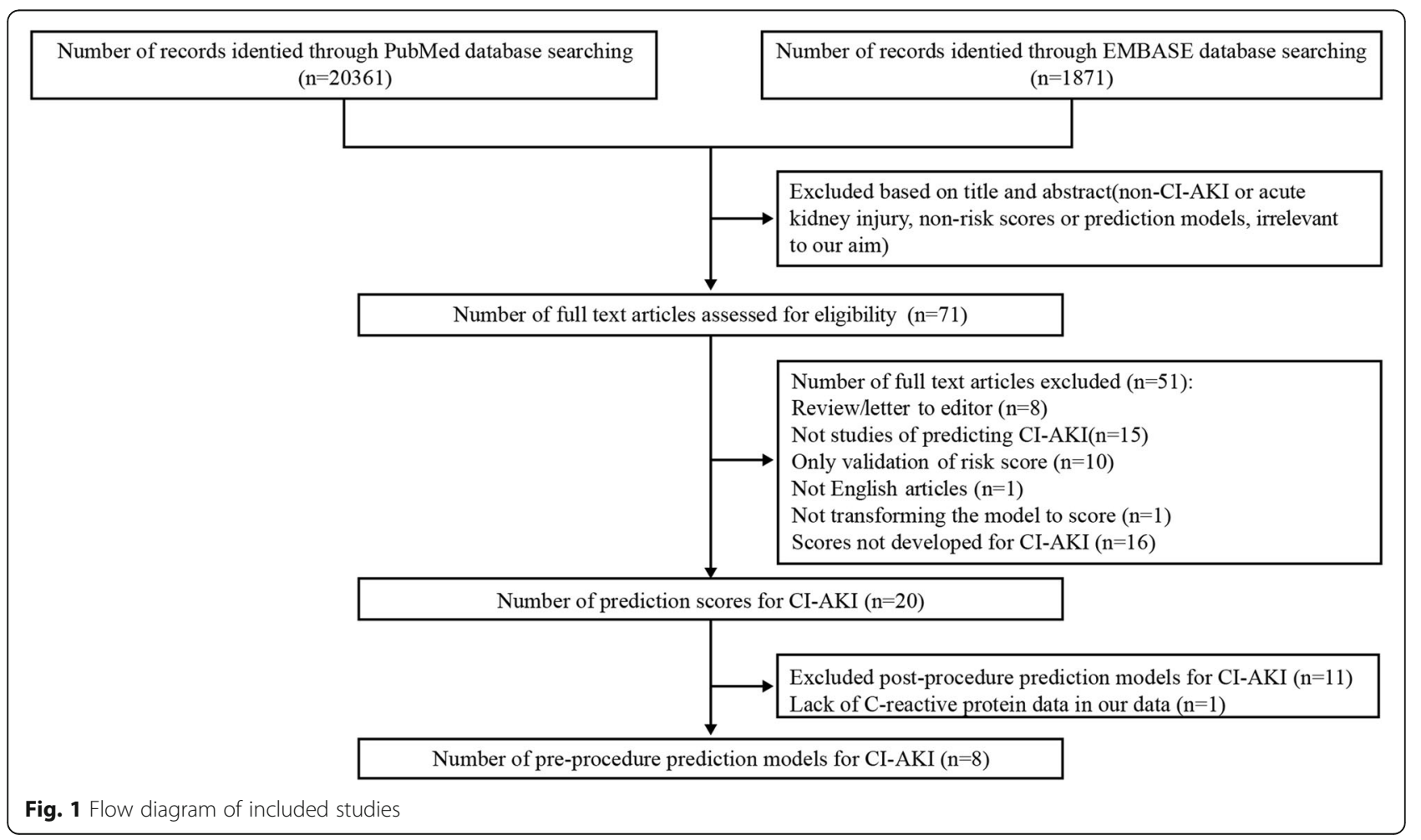


Table 2 Characteristics of risk scores development and validation studies for contrast-induced acute kidney injury

\begin{tabular}{|c|c|c|c|c|c|c|c|c|}
\hline Scores & Study population & $\begin{array}{l}\text { No. of } \\
\text { centers }\end{array}$ & $\begin{array}{l}\text { No. of } \\
\text { developing } \\
\text { patients }\end{array}$ & $\begin{array}{l}\text { Incidence } \\
\text { of Cl-AKI (\%) }\end{array}$ & $\begin{array}{l}\text { Model } \\
\text { Discrimination }\end{array}$ & $\begin{array}{l}\text { No. of } \\
\text { validation } \\
\text { patients }\end{array}$ & $\begin{array}{l}\text { Incidence } \\
\text { of Cl-AKI } \\
\text { (\%) in } \\
\text { validation }\end{array}$ & $\begin{array}{l}\text { Model } \\
\text { Discrimination } \\
\text { in validation }\end{array}$ \\
\hline Maioli & $\begin{array}{l}\text { patients undergoing coronary } \\
\text { angiography or } \mathrm{PCl}\end{array}$ & single & 1218 & 9.4 & $\begin{array}{l}\text { C-statistic = } \\
0.85\end{array}$ & 502 & 10.8 & C-statistic $=0.82$ \\
\hline Chen & patients undergoing $\mathrm{PCl}$ & single & 1500 & 16.4 & $\begin{array}{l}\text { C-statistic }= \\
0.82\end{array}$ & 1000 & 17.2 & C-statistic $=0.82$ \\
\hline Liu & $\begin{array}{l}\text { patients with coronary chronic } \\
\text { total occlusion who underwent PCI }\end{array}$ & single & 495 & 3.0 & $\begin{array}{l}\text { C-statistic } \\
=0.789\end{array}$ & 233 & $\begin{array}{l}\text { not } \\
\text { reported }\end{array}$ & $\begin{array}{l}\text { C-statistic } \\
=0.864\end{array}$ \\
\hline Lian & $\begin{array}{l}\text { patients aged }>65 \text { years and } \\
\text { who had undergone CAG }\end{array}$ & single & 759 & 6.3 & $\begin{array}{l}\text { C-statistic } \\
=0.727\end{array}$ & 527 & 6.6 & $\begin{array}{l}\text { C-statistic } \\
=0.695\end{array}$ \\
\hline Lin & $\begin{array}{l}\text { patients who underwent coronary } \\
\text { angiography or PCI if they were } \\
\text { diagnosed with STEMI and presented } \\
\text { quite high risk in those with NSTE-ACS }\end{array}$ & single & 461 & 6.9 & not reported & 231 & 9.9 & $\begin{array}{l}\text { C-statistic } \\
=0.832\end{array}$ \\
\hline Ghani & patients undergoing $\mathrm{PCl}$ & single & 247 & 5.52 & not reported & 100 & 5.0 & C-statistic $=0.61$ \\
\hline Inohara & patients undergoing $\mathrm{PCl}$ & $\begin{array}{l}\text { multi- } \\
\text { center }\end{array}$ & 3957 & 9 & not reported & 1979 & $\begin{array}{l}\text { not } \\
\text { reported }\end{array}$ & 0.799 \\
\hline Zeng & $\begin{array}{l}\text { patients who had been diagnosed } \\
\text { with diabetes and underwent CAG/PCI }\end{array}$ & single & 771 & 3.9 & not reported & 386 & 3.9 & $\begin{array}{l}\text { C-statistic }= \\
0.813\end{array}$ \\
\hline
\end{tabular}

CI-AKI Contrast-induced acute kidney injury, PCI Percutaneous coronary intervention, STEMI ST-segment elevation myocardial infarction, NSTE-ACS Non-ST-segment elevation acute coronary syndrome, CAG Elective coronary angiography, AMI Acute myocardial infarction

calibration for CI-AKI, but the Chen and Ghani calibrations express a lack of fit by any definition $(P<0.05)$ (Table 5). For CI-AKI broad1, the AUC for all scores ranged from 0.44 to 0.52 , with all risk scores having a low prediction accuracy. For CI-AKI broad2, all risk scores did not show better prediction accuracy, with Cstatistics ranging from 0.51 to 0.57 . And the scores showed relatively good discrimination. When using the narrow definition of CI-AKI, the C-statistic of Maioli, Chen, Liu, and Ghani were $\geq 0.7$, while of Lian and Lin was between 0.5 and 0.6, of Inohara was 0.5.

\section{Discussion}

Our study is the first to review the CI-AKI preoperative risk score and perform external validation. In this study, we first systematically evaluated the pre-operative risk scores for CI-AKI. 8 risk scores are only available for patients undergoing coronary angiography or PCI, but not for other procedures such as computed tomography (CT). Only one score was established in a multi-center population, and only Chen score was externally validated. Then we validated these scores externally using the cohort of our hospital. Using the definitions of CIAKI broad, all C-statistics were less than 0.6 , while $\mathrm{C}$ statistic was less than 0.8 using the definition of CI-AKInarrow. The identification results were widely disadvantageous for CI-AKI. Only three risk scores have a CIAKI stenosis C-statistic $>0.7$, and the Maioli score had the best discrimination and calibration among them.

Many prediction models and scores for CI-AKI have been established, but we only focus on the pre-operative prediction scores in this study because they have better

Table 3 Definitions of contrast-induced acute kidney injury in the original studies of pre-operative risk scores

\begin{tabular}{ll}
\hline Scores & Cl-AKI definitions \\
\hline Maioli & an absolute increase in the serum creatinine level by $\geq 0.5 \mathrm{mg} / \mathrm{dL}$ from the baseline within 5 days \\
Chen & an increase in the serum creatinine level by $\geq 0.5 \mathrm{mg} / \mathrm{dL}$ or $\geq 25 \%$ from the baseline within 5 days after $\mathrm{PCl}$ \\
Liu & an absolute increase in the serum creatinine level by $\geq 0.5 \mathrm{mg} / \mathrm{dL}$ from the baseline within $48-72 \mathrm{~h}$ after $\mathrm{CM}$ exposure \\
Lian & an increase in the serum creatinine level by $>0.3 \mathrm{mg} / \mathrm{dL}$ or $\geq 50 \%$ from the baseline within $48-72 \mathrm{~h}$ after $\mathrm{CM}$ exposure \\
Lin & an absolute increase in the serum creatinine level by $\geq 0.5 \mathrm{mg} / \mathrm{dL}$ from the baseline within $72 \mathrm{~h}$ after $\mathrm{CM}$ exposure \\
Ghani & an increase in the serum creatinine level by $\geq 0.5 \mathrm{mg} / \mathrm{dL}$ from the baseline within $48 \mathrm{~h}$ \\
Inohara & an increase in the serum creatinine level by $\geq 0.3 \mathrm{mg} / \mathrm{dL}$ or $\geq 50 \%$ from the baseline after $\mathrm{PCl}$ \\
Zeng & an absolute increase in the serum creatinine level by $\geq 0.5 \mathrm{mg} / \mathrm{dL}$ from the baseline within $48-72 \mathrm{~h}$ after CM exposure
\end{tabular}


Table 4 Baseline clinical features of the study population

\begin{tabular}{|c|c|c|c|c|c|c|c|}
\hline Variable & $\begin{array}{l}\text { All patients } \\
(n=2669)\end{array}$ & $\begin{array}{l}\mathrm{Cl}^{-A K I_{1}} \\
(n=178)\end{array}$ & $\begin{array}{l}\text { Non-Cl-AKI } 1 \\
(n=2491)\end{array}$ & $\begin{array}{l}\mathrm{Cl}-\mathrm{AKI}_{2} \\
(n=39)\end{array}$ & $\begin{array}{l}\text { Non-Cl-AKI } \\
(n=2630)\end{array}$ & $\begin{array}{l}\mathrm{Cl}-\mathrm{AKI}_{3} \\
(n=18)\end{array}$ & $\begin{array}{l}\text { Non-Cl-AKI } \\
(n=2651)\end{array}$ \\
\hline Age (years) & $63.31 \pm 10.21$ & $63.53 \pm 9.38$ & $63.29 \pm 10.27$ & $64.49 \pm 9.35$ & $63.29 \pm 10.23$ & $69.38 \pm 8.05^{*}$ & $63.27 \pm 10.21$ \\
\hline Female sex & $926(34.75 \%)$ & $47(26.40 \%)^{*}$ & $879(35.29 \%)$ & $10(25.64 \%)$ & $916(34.83 \%)$ & $6(33.33 \%)$ & $920(34.70 \%)$ \\
\hline Weight (kg) & $64.46 \pm 11.25$ & $63.38 \pm 10.78$ & $64.54 \pm 11.28$ & $63.44 \pm 11.85$ & $64.48 \pm 11.24$ & $64.84 \pm 14.99$ & $64.46 \pm 11.22$ \\
\hline Diabetes (\%) & 1045 (39.15\%) & $68(38.20 \%)$ & 977 (39.22\%) & $17(43.59 \%)$ & 1028 (39.08\%) & $9(50.00 \%)$ & $1036(39.08 \%)$ \\
\hline Hypertension (\%) & $1467(54.96 \%)$ & 97 (54.49\%) & $1370(55.00 \%)$ & $20(51.28 \%)$ & 1447 (55.02\%) & 7 (38.89\%) & $1460(55.07 \%)$ \\
\hline Previous PCI (\%) & $119(4.46 \%)$ & $5(2.81 \%)$ & $114(4.58 \%)$ & $2(5.13 \%)$ & $117(4.45 \%)$ & $1(5.56 \%)$ & $118(4.45 \%)$ \\
\hline Baseline Scr ( $\mu \mathrm{mol} / \mathrm{L})$ & $85.93 \pm 42.25$ & $75.38 \pm 57.39^{*}$ & $86.68 \pm 40.86$ & $97.92 \pm 114.24$ & $85.75 \pm 40.26$ & $156.56 \pm 149.07^{*}$ & $85.45 \pm 40.25$ \\
\hline Increased Scr ( $\mu \mathrm{mol} / \mathrm{L})$ & $83.14 \pm 41.94$ & $104.11 \pm 73.39^{*}$ & $81.65 \pm 38.31$ & $149.54 \pm 140.09^{*}$ & $82.16 \pm 37.88$ & $229.28 \pm 176.18^{*}$ & $82.15 \pm 37.76$ \\
\hline eGFR (mL/min/1.73 m2) & $87.24 \pm 35.12$ & $113.42 \pm 52.27^{*}$ & $85.36 \pm 32.79$ & $117.78 \pm 73.29^{*}$ & $86.78 \pm 34.06$ & $55.31 \pm 26.81^{*}$ & $87.45 \pm 35.07$ \\
\hline $\mathrm{CrCl}$ (mL/minute) & $74.28 \pm 27.01$ & $90.49 \pm 37.21^{*}$ & $73.12 \pm 25.75$ & $93.53 \pm 56.38^{*}$ & $73.99 \pm 26.25$ & $47.33 \pm 23.61^{*}$ & $74.46 \pm 26.94$ \\
\hline $\mathrm{HDL}(\mathrm{mmol} / \mathrm{L})$ & $1.17 \pm 0.28$ & $1.17 \pm .287$ & $1.17 \pm 0.28$ & $1.17 \pm 0.29$ & $1.17 \pm 0.28$ & $1.14 \pm 0.29$ & $1.17 \pm 0.28$ \\
\hline LVEF (\%) & $56.64 \pm 16.95$ & $55.14 \pm 17.49$ & $56.75 \pm 16.90$ & $55.18 \pm 14.94$ & $56.66 \pm 16.98$ & $53.06 \pm 18.64$ & $56.66 \pm 16.93$ \\
\hline Myocardial infarction (\%) & $652(24.43 \%)$ & $43(24.16 \%)$ & $609(24.45 \%)$ & $12(30.77 \%)$ & $640(24.33 \%)$ & $6(33.33 \%)$ & $646(24.37 \%)$ \\
\hline Hypotension (\%) & $139(5.21 \%)$ & $15(8.43 \%)^{*}$ & $124(4.98 \%)$ & $3(7.69 \%)$ & $136(5.17 \%)$ & $2(11.11 \%)$ & $137(5.17 \%)$ \\
\hline Anemia (\%) & $817(30.61 \%)$ & $70(39.33 \%)^{*}$ & 747 (29.99\%) & $11(28.21 \%)$ & $806(30.65 \%)$ & $6(33.33 \%)$ & $811(30.59 \%)$ \\
\hline Urgent PCI (\%) & $13(0.49 \%)$ & $0(0.00 \%)$ & $13(0.52 \%)$ & $0(0.00 \%)$ & $13(0.49 \%)$ & 0 & $13(0.49 \%)$ \\
\hline Shock (\%) & $20(0.75 \%)$ & $1(0.56 \%)$ & $19(0.76 \%)$ & $1(2.56 \%)$ & 19 (0.72\%) & $1(5.56 \%)$ & $19(0.72 \%)$ \\
\hline CHF (\%) & $306(11.46 \%)$ & $26(14.61 \%)$ & $280(11.24 \%)$ & $5(12.82 \%)$ & $301(11.44 \%)$ & $3(16.67 \%)$ & $303(11.43 \%)$ \\
\hline IABP (\%) & $13(0.49 \%)$ & $1(0.56 \%)$ & $12(0.48 \%)$ & $0(0.00 \%)$ & $13(0.49 \%)$ & 0 & $13(0.49 \%)$ \\
\hline Multivessel PCI (\%) & $203(7.60 \%)$ & $9(5.06 \%)$ & $194(7.79 \%)$ & $2(5.13 \%)$ & $201(7.64 \%)$ & $2(11.11 \%)$ & $201(7.58 \%)$ \\
\hline ACS (\%) & $929(34.81 \%)$ & $61(34.27 \%)$ & $868(34.85 \%)$ & $16(41.03 \%)$ & $913(34.71 \%)$ & $5(27.78 \%)$ & $924(34.85 \%)$ \\
\hline Previous procedure (\%) & $231(8.65 \%)$ & 16 (8.99\%) & $215(8.63 \%)$ & $2(5.13 \%)$ & $229(8.70 \%)$ & 0 & 231 (8.71\%) \\
\hline
\end{tabular}

CI-AKI Contrast-induced acute kidney injury, CI-AKI1 CI-AKI broad1, CI-AKI2 CI-AKI broad2, CI-AKI3 Cl-AKI narrow, PCI Percutaneous coronary intervention, SCr Serum creatinine, eGFR Estimated glomerular filtration rate, $\mathrm{CrCl}$ creatinine clearance, $H D L$ High-density lipoprotein, $L V E F$ Left ventricular ejection function, $C H F$ Congestive heart failure, IABP Intra-aortic balloon pump, ACS Acute coronary syndrome

clinical applicability and a series of precautions can be taken to reduce the risk of CI-AKI once identified as a high-risk population. Common interventions include hydration therapy, drug interventions such as alprostadil, discontinuation of nephrotoxic drugs, use of smaller and safer $\mathrm{CM}$, and dialysis treatment [39, 40]. In addition, scores are simpler, more intuitive, and more acceptable to doctors than the original models (such as decision trees and random forests).

Baseline renal function, age and diabetes are common risk factors for pre-operative scores as they have been reported as important risk factors in many prvious studies $[16,40]$. Therefore, these risk factors need to attract more attention in establishing predictive scores in the future. For the 8 scores, the Inohara score was developed in the Japan Cardiovascular Database Keio Inter-hospital Cardiovascular Studies (JCD-KICS), a prospective multi-center registry, and the remaining scores were single-center studies, which limit their generalizability. More importantly, seven of risk scores were only validated internally but not externally, so they may not be applicable to other centers due to demographic differences.

The incidence of CI-AKI was extensive in 8 scores studies, the lowest in Liu's study (3.0\%) and the highest in Chen's study (16.4\%). Interestingly, they were all based on the Chinese population, but the incidence was five times different. In fact, the incidence of CI-AKI depends to a large extent on the definition used. Liu defined CI-AKI as an absolute increase in $\mathrm{Scr} \geq 0.5 \mathrm{mg} / \mathrm{dL}$ over the baseline value within 48-72 $\mathrm{h}$ after CM exposure. Chen defined CI-AKI as an increase in Scr from pre-PCI (baseline) level to either $\geq 25 \%$ or $\geq 0.5 \mathrm{mg} / \mathrm{dL}$ within 5 days after PCI. Comparing these two definitions, it can be found Liu's definition is stricter, regardless of the change of Scr or the time of CI-AKI, so the incidence of CI-AKI is lower.

There is no uniform definition of CI-AKI now, as shown in the Table 1, the definitions of CI-AKI in the score studies were quite different. Interestingly, none of the pre-operative risk scores in this study used the definition of CI-AKI published by CMSC. More than half of 


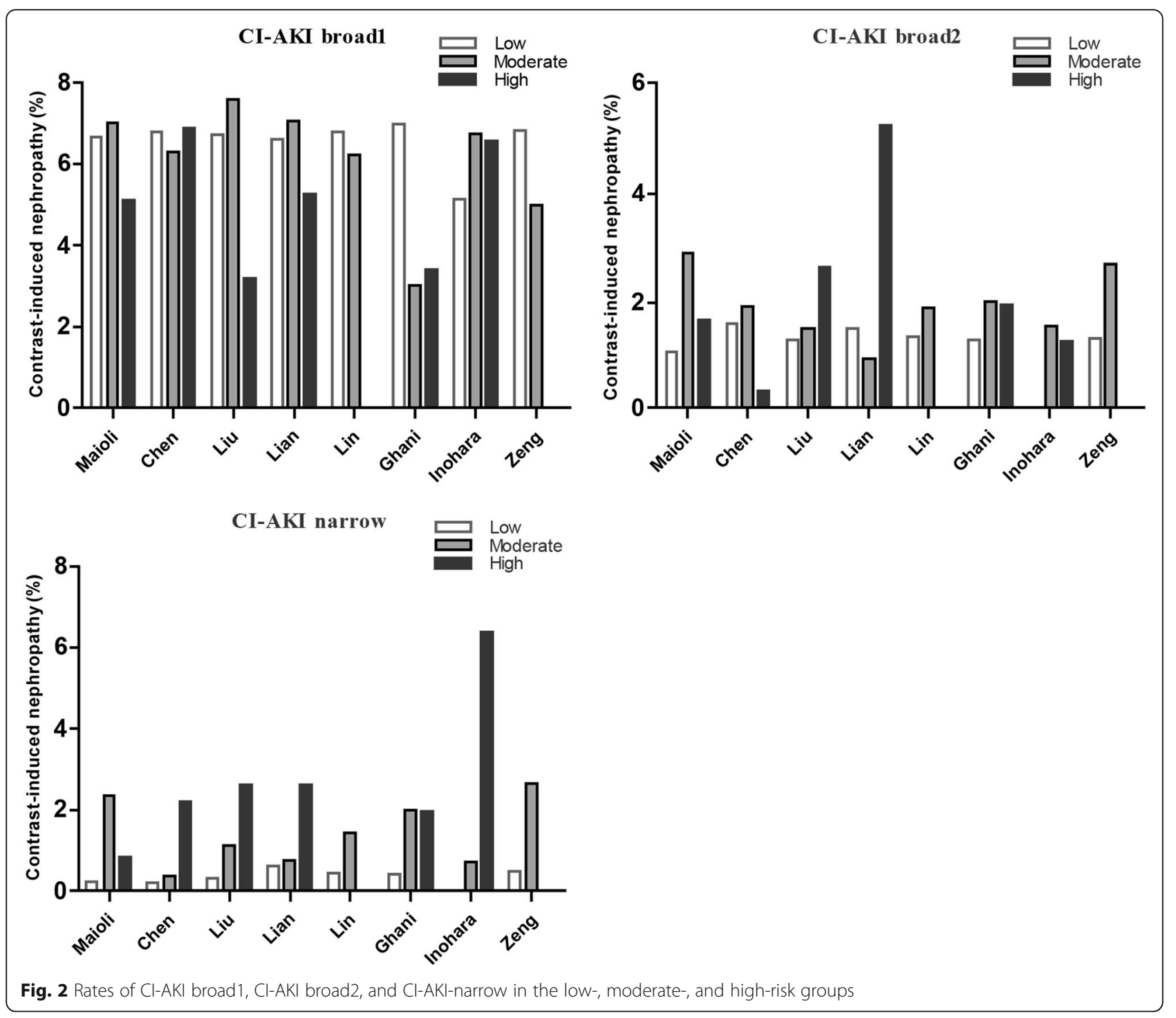

Table 5 Calibration and discriminatory capacity of Cl-AKI risk scores

\begin{tabular}{|c|c|c|c|c|c|c|c|c|}
\hline & Maioli & Chen & Liu & Lian & Lin & Ghani & Inohara & Zeng \\
\hline \multicolumn{9}{|l|}{ Cl-AKI broad1 } \\
\hline C-statistic $(95 \% \mathrm{Cl})$ & 0.49 & $0.49(0.45-0.54)$ & $0.49(0.46-0.52)$ & $0.46(0.42-0.50)$ & $0.49(0.46-0.52)$ & $0.44(0.40-0.48)$ & $0.52(0.48-0.56)$ & $0.47(0.43-0.52)$ \\
\hline $\mathrm{HL}(P)$ & 0.94 & $<0.05$ & 0.67 & 0.47 & 0.47 & $<0.05$ & 0.35 & 0.56 \\
\hline \multicolumn{9}{|l|}{ Cl-AKI broad2 } \\
\hline C-statistic (95\%Cl) & 0.57 & $0.55(0.44-0.66)$ & $0.54(0.46-0.62)$ & $0.51(0.42-0.59)$ & $0.53(0.46-0.60)$ & $0.53(0.44-0.62)$ & $0.55(0.46-0.64)$ & $0.56(0.47-0.62)$ \\
\hline $\mathrm{HL}(P)$ & 0.91 & $<0.05$ & 0.5 & 0.39 & 0.51 & $<0.05$ & 0.08 & 0.75 \\
\hline \multicolumn{9}{|l|}{ Cl-AKI narrow } \\
\hline C-statistic $(95 \% \mathrm{Cl})$ & 0.76 & $0.76(0.63-0.89)$ & $0.70(0.58-0.82)$ & $0.68(0.57-0.78)$ & $0.63(0.51-0.75)$ & $0.71(0.59-0.84)$ & $0.50(0.36-0.65)$ & $0.63(0.49-0.78)$ \\
\hline $\mathrm{HL}(P)$ & 0.91 & $<0.05$ & 0.49 & 0.35 & 0.46 & $<0.05$ & 0.16 & 0.75 \\
\hline
\end{tabular}

CI-AKI Contrast-induced acute kidney injury, HL Hosmer-Lemeshow test 
the models defined the CI-AKI as an absolute elevation in Scr of $0.5 \mathrm{mg} / \mathrm{dL}$ when compared with basic Scr. Some studies found the CI-AKI definition of $25 \%$ increase in Scr may not be possible in emergency department patients with normal renal function [16, 41]. The definitions can greatly affect the incidence of CI-AKI and the validation results, so in this study we chose 3 definition for a Comprehensive verification.

In our study, all pre-operative risk scores did not show good discrimination when using the CI-AKI broads, but they had better predictive power for CI-AKI narrow. Seven of the scores were validated externally for the first time, and the Chen score was validated externally by one cohort from Guangdong General Hospital [38]. It has good predictive ability (C-statistic $=0.828$, and 0.746 , respectively) with the narrow definition (an increase in Scr $\geq 0.5 \mathrm{mg} / \mathrm{dL}$ ) and poor predictive ability (C-statistic = 0.555 ) with broad definition (an increase in Scr $\geq 25 \%$ or $\geq 0.5 \mathrm{mg} / \mathrm{dL}$ ). Our results were consistent with their results. What's more, some previous studies have found similar results. We have previously validated the Mehran score and the results suggested that when using the narrow definition ( $\mathrm{Scr} \geq 0.5 \mathrm{mg} / \mathrm{dL}$ ), the Mehran score indicated a good discrimination (C-statistic $=0.726$ ), and when using the broad definition ( $\mathrm{Scr} \geq 25 \%$ or $\geq 0.5 \mathrm{mg}$ / $\mathrm{dL})$, discrimination was limited $(\mathrm{C}$-statistic $=0.497)$ [12]. In a study by Yuan-hui Liu and colleagues, they compared the prognostic value of 6 different risk scores for CI-AKI postoperative scores in 422 consecutive patients with ST-elevation myocardial infarction who underwent primary PCI. These risk scores demonstrated poor discriminatory ability for CI-AKI broad but good for CIAKI narrow [38].

The CHA2DS2-VASC risk score (CVRS) and the Global Registry for Acute Coronary Events (Grace) were also used to predict CI-AKI. Yong Wang and colleagues found that CVRS, developed for stratification of embolic risk in patients with atrial fibrillation (AF) to provide further optimized anticoagulant therapy, can be used as a simple preoperative predictor of CI-AKI in patients with CTO undergoing PCI (C-statistic $=0.742)$ [42], which was also confirmed in patients with acute STelevation myocardial infarction and acute coronary syndrome [43-45]. In addition, the Grace score was also considered to be a strong predictor of CI-AKI development in patients $[46,47]$.

Further research is needed to develop pre-operative risk scores of contrast-induced acute kidney injury that should use standard definitions to select and measure risk factors in order to reduce misclassification bias and heterogeneity. Reported pre-operative risk scores of contrast-induced acute kidney injury need to be externally validated by multi-center cohorts which can ensure better clinical applicability of risk scores. In addition, Scr threshold for the definition of contrast-induced acute kidney injury is significant to the results of pre-operative risk scores and needs to be accurately defined in the future directions.

\section{Limitations}

There are several limitations in our research explanation that need to be pointed out. First, this is a retrospective single-center study whose inherent weakness are unavoidable. Second, we did not evaluate the end outcomes such as end-stage renal failure and death. Third, we included patients who underwent coronary angiography and PCI, but some scores excluded patients with coronary angiography, some of whom included specific populations, such as the elderly and diabetes; thus, there will be some differences between the characteristics of the development population and the validation population.

\section{Conclusion}

We first performed a review for pre-operative risk scores for CI-AKI, most of which were developed in a single center, lacking external validation, and all of which were focused on patients undergoing coronary angiography or $\mathrm{PCI}$, ignoring other procedures such as contrast enhanced computer tomography (CT). And for the first time, seven of the pre-operative risk score is externally validated, and the validation results are affected by the definition of CI-AKI. Compared with the broad definition of CI-AKI, all pre-operative risk scores have better predictive ability with the definition of CI-AKI-narrow. They expressed poor discriminations for the CI-AKI broads. When using the CI-AKI-narrow, the Maioli score has the best discrimination and calibration, and the 3 scores (the Maioli, Chen, and Ghani scores) have acceptable discriminating power $(\mathrm{C}$-statistic $>0.7)$.

\section{Supplementary information}

Supplementary information accompanies this paper at https://doi.org/10. 1186/s12882-020-1700-8.

Additional file 1: Table S1. Search strategy for contrast-induced acute kidney injury (Cl-AKI) risk prediction models. Figure S1. Study flow chart. Additional file 2: Data.

\section{Abbreviations \\ AF: Atrial fibrillation; AMl: Acute myocardial infarction; CAG: Elective coronary angiography; C-G: The Cockcroft-Gault equation; CHF: Congestive heart failure; Cl-AKI: Contrast-induced acute kidney injury; $\mathrm{CrCl}$ : Creatinine clearance; CT: Computed tomography; eGFR: Estimated glomerular filtration rate; MDRD: The Modification of Diet in Renal Disease equation; NSTE- ACS: Non-ST-segment elevation acute coronary syndrome; PCl: Percutaneous coronary intervention; Scr: Serum creatinine; CM: Contrast media; CKD: Chronic kidney disease; SD: Standard deviation; STEMI: ST-segment elevation myocardial infarction}

\section{Acknowledgments}

We thank Shanghai Lejiu Healthcare Technology Co, Ltd. for his assistance in data extraction. 


\section{Authors' contributions}

XCZ, WJY and GZ designed the study. LYZ, MCL, LHC and HQY collected the data. WJY, GZ, YLX, JW and SRZ analyzed the data. WJY and GZ drafted the first version of the manuscript. $\mathrm{KL}$ and $\mathrm{CH}$ modified the manuscript. XCZ supervised the study and contributed to the conception and design of the study, the analysis and interpretation of the data, and writing of the manuscript. All authors contributed to the interpretation of the data and critically reviewed the manuscript. All authors read and approved the final manuscript.

\section{Funding}

This study was supported by National Natural Science Foundation of China (No. 81773822, 81973400), Hunan Provincial Natural Science Foundation of China (No. 2018JJ6051) and Hospital Pharmacy of Hunan Pharmaceutical Society Research Fund (No. hn2017003). The funding sources were not involved in any part of the study design or the decision to submit the manuscript for publication.

\section{Availability of data and materials}

All data generated or analysed during this study are included in this published article and its supplementary information files.

\section{Ethics approval and consent to participate}

The study protocol was approved by the Medical Ethical Committee in the third Xiangya hospital of central south university, (No. 2016-S160). Due to the retrospective nature of the study, this study was performed with an approved waiver of informed consent.

\section{Consent for publication}

Not applicable.

\section{Competing interests}

The authors declare that they have no competing interests.

Received: 22 August 2019 Accepted: 20 January 2020

Published online: 10 February 2020

\section{References}

1. Christiansen C. X-ray contrast media--an overview. Toxicology. 2005;209(2): 185-7.

2. Rosado IA, Dona DI, Cabanas MR, Moya QM, Garcia-Aviles C, Garcia NI, et al. Clinical practice guidelines for diagnosis and Management of Hypersensitivity Reactions to contrast media. J Investig Allergol Clin Immunol. 2016:26(3):144-55 2-155.

3. Nash K, Hafeez A, Hou S. Hospital-acquired renal insufficiency. Am J Kidney Dis. 2002:39(5):930-6.

4. Mitchell AM, Jones AE, Tumlin JA, Kline JA. Incidence of contrast-induced nephropathy after contrast-enhanced computed tomography in the outpatient setting. Clin J Am Soc Nephrol. 2010;5(1):4-9.

5. Azzalini L, Spagnoli V, Ly HQ. Contrast-induced nephropathy: from pathophysiology to preventive strategies. Can J Cardiol. 2016;32(2):247-55.

6. Maliborski A, Zukowski P, Nowicki G, Boguslawska R. Contrast-induced nephropathy--a review of current literature and guidelines. Med Sci Monit. 2011;17(9):A199-204.

7. Tepel M, Aspelin P, Lameire N. Contrast-induced nephropathy: a clinical and evidence-based approach. Circulation. 2006;113(14):1799-806.

8. Azzalini L. The clinical significance and management implications of chronic Total occlusion associated with surgical coronary artery revascularization. Can J Cardiol. 2016:32(11):1286-9.

9. Silver SA, Shah PM, Chertow GM, Harel S, Wald R, Harel Z. Risk prediction models for contrast induced nephropathy: systematic review. BMJ. 2015;351:h4395.

10. Ali A, Bhan C, Malik MB, Ahmad MQ, Sami SA. The prevention and Management of Contrast-induced Acute Kidney Injury: a mini-review of the literature. Cureus. 2018;10(9):e3284.

11. Mehran R, Aymong ED, Nikolsky E, Lasic Z, lakovou I, Fahy M, et al. A simple risk score for prediction of contrast-induced nephropathy after percutaneous coronary intervention: development and initial validation. J Am Coll Cardiol. 2004:44(7):1393-9.

12. Yin WJ, Zhou LY, Li DY, Liu K, Hu C, Zuo XC. Efficiency analysis of Mehran score on the risk prediction of contrast-induced nephropathy in Chinese population. J Southeast University (Medical Edition). 2018;37(06):998-1001.
13. Cockcroft DW, Gault MH. Prediction of creatinine clearance from serum creatinine. Nephron. 1976;16(1):31-41.

14. Levey AS, Bosch JP, Lewis JB, Greene T, Rogers N, Roth D. A more accurate method to estimate glomerular filtration rate from serum creatinine: a new prediction equation. Modification of diet in renal disease study group. Ann Intern Med. 1999:130(6):461-70.

15. Stacul F, van der Molen AJ, Reimer P, Webb JA, Thomsen HS, Morcos SK, et al. Contrast induced nephropathy: updated ESUR contrast media safety committee guidelines. Eur Radiol. 2011;21(12):2527-41.

16. Budano C, Levis M, D'Amico M, Usmiani T, Fava A, Sbarra P, et al. Impact of contrast-induced acute kidney injury definition on clinical outcomes. Am Heart J. 2011;161(5):963-71.

17. Hanley JA, MCNeil BJ. The meaning and use of the area under a receiver operating characteristic (ROC) curve. Radiology. 1982;143(1):29-36.

18. Chongyang Duan MYCM. A new pre-procedure risk score for predicting contrast-induced acute kidney injury. Can J Cardiol. 2017;33(6):714.

19. Guo B, Ouyang F, Yang S, Liu Z, Lin S, Meng W, et al. Development of a preprocedure nomogram for predicting contrast-induced acute kidney injury after coronary angiography or percutaneous coronary intervention. Oncotarget. 2017;8(43):75087.

20. Yuan Y, Qiu H, Song L, Hu X, Luo T, Zhao X, et al. A new risk factor profile for contrast-induced acute kidney injury in patients who underwent an emergency percutaneous coronary intervention. Angiology. 2017:69(6):523-31.

21. Ji L, Su X, Qin W, Mi X, Liu F, Tang X, et al. Novel risk score of contrastinduced nephropathy after percutaneous coronary intervention. Nephrology. 2015;20(8):544-51.

22. Victor SM, Gnanaraj A, VijayaKumar S, Deshmukh R, Kandasamy M, Janakiraman E, et al. Risk scoring system to predict contrast induced nephropathy following percutaneous coronary intervention. Indian Heart J. 2014;66(5):517-24.

23. Gao Y, Li D, Cheng H, Chen Y. Derivation and validation of a risk score for contrast-induced nephropathy after cardiac catheterization in Chinese patients. Clin Exp Nephrol. 2014;18(6):892-8.

24. Tziakas D, Chalikias G, Stakos D, Apostolakis S, Adina T, Kikas P, et al. Development of an easily applicable risk score model for contrast-induced nephropathy prediction after percutaneous coronary intervention. Int 」 Cardiol. 2013;163(1):46-55.

25. Fu N, Li X, Yang S, Chen Y, Li Q, Jin D, et al. Risk score for the prediction of contrast-induced nephropathy in elderly patients undergoing percutaneous coronary intervention. Angiology. 2012;64(3):188-94.

26. Chong E, Shen L, Poh KK, Tan HC. Risk scoring system for prediction of contrast-induced nephropathy in patients with pre-existing renal impairment undergoing percutaneous coronary intervention. Singap Med J. 2012;53(3):164-9.

27. Bartholomew BA, Harjai KJ, Dukkipati S, Boura JA, Yerkey MW, Glazier S, et al. Impact of nephropathy after percutaneous coronary intervention and a method for risk stratification. Am J Cardiol. 2004;93(12):1515-9.

28. Marenzi G, Lauri G, Assanelli E, Campodonico J, De Metrio M, Marana I, et al. Contrast-induced nephropathy in patients undergoing primary angioplasty for acute myocardial infarction. J Am Coll Cardiol. 2004;44(9):1780-5.

29. Lazaros G, Zografos T, Oikonomou E, Siasos G, Georgiopoulos G, Vavuranakis $\mathrm{M}$, et al. Usefulness of C-reactive protein as a predictor of contrast-induced nephropathy after percutaneous coronary interventions in patients with acute myocardial infarction and presentation of a new risk score (Athens CIN score). Am J Cardiol. 2016;118(9):1329-33.

30. Maioli M, Toso A, Gallopin M, Leoncini M, Tedeschi D, Micheletti C, et al. Preprocedural score for risk of contrast-induced nephropathy in elective coronary angiography and intervention. J Cardiovasc Med (Hagerstown). 2010;11(6):444-9.

31. Chen YL, Fu NK, Xu J, Yang SC, Li S, Liu YY, et al. A simple preprocedural score for risk of contrast-induced acute kidney injury after percutaneous coronary intervention. Catheter Cardiovasc Interv. 2014;83(1):E8-16.

32. Liu Y, Liu YH, Chen JY, Tan N, Zhou YL, Li HL, et al. A simple pre-procedural risk score for contrast-induced nephropathy among patients with chronic total occlusion undergoing percutaneous coronary intervention. Int J Cardiol. 2015;180:69-71.

33. Lian D, Liu Y, Liu YH, Li HL, Duan CY, Yu DQ. Pre-procedural risk score of contrast-induced nephropathy in elderly patients undergoing elective coronary angiography. Int Heart J. 2017;58(2):197-204.

34. Lin KY, Zheng WP, Bei WJ, Chen SQ, Islam SM, Liu Y, et al. A novel risk score model for prediction of contrast-induced nephropathy after emergent percutaneous coronary intervention. Int J Cardiol. 2017;230:402-12. 
35. Ghani AA, Tohamy KY. Risk score for contrast induced nephropathy following percutaneous coronary intervention. Saudi J Kidney Dis Transpl. 2009;20(2):240-5

36. Inohara T, Kohsaka S, Abe T, Miyata H, Numasawa Y, Ueda I, et al. Development and validation of a pre-percutaneous coronary intervention risk model of contrast-induced acute kidney injury with an integer scoring system. Am J Cardiol. 2015;115(12):1636-42.

37. Zeng JF, Chen SQ, Ye JF, Chen Y, Lei L, Liu XQ, et al. A simple risk score model for predicting contrast-induced nephropathy after coronary angiography in patients with diabetes. Clin Exp Nephrol. 2019;23(7):969.

38. Liu YH, Liu Y, Zhou YL, He PC, Yu DQ, Li LW, et al. Comparison of different risk scores for predicting contrast induced nephropathy and outcomes after primary percutaneous coronary intervention in patients with ST elevation myocardial infarction. Am J Cardiol. 2016;117(12):1896-903.

39. Group KAW. KDIGO clinical practice guideline for acute kidney injury. Kidney Int Suppl. 2012;17:1-138.

40. Hossain MA, Costanzo E, Cosentino J, Patel C, Qaisar H, Singh V, et al. Contrast-induced nephropathy: pathophysiology, risk factors, and prevention. Saudi J Kidney Dis Transpl. 2018;29(1):1-9.

41. Sinert R, Brandler E, Subramanian RA, Miller AC. Does the current definition of contrast-induced acute kidney injury reflect a true clinical entity? Acad Emerg Med. 2012;19(11):1261-7.

42. Wang Y, Zhao HW, Zhang XJ, Chen BJ, Yu GN, Hou AJ, et al. CHA2DS2VASC score as a preprocedural predictor of contrast-induced nephropathy among patients with chronic total occlusion undergoing percutaneous coronary intervention: a single-center experience. BMC Cardiovasc Disord. 2019;19(1):74.

43. Cicek G, Yildirim E. CHA2DS2-VASc score predicts contrast-induced nephropathy in patients with ST-segment elevation myocardial infarction, who have undergone primary percutaneous coronary intervention. Kardio Pol. 2018;76(1):91-8.

44. Kurtul A, Yarlioglues M, Duran M. Predictive value of CHA2DS2-VASC score for contrast-induced nephropathy after percutaneous coronary intervention for acute coronary syndrome. Am J Cardiol. 2017;119(6):819-25.

45. Chou RH, Huang PH, Hsu CY, Leu HB, Huang SS, Huang CC, et al. CHADS2 score predicts risk of contrast-induced nephropathy in stable coronary artery disease patients undergoing percutaneous coronary interventions. J Formos Med Assoc. 2016;115(7):501-9.

46. Liu YH, Liu Y, Tan N, Chen JY, Chen J, Chen SH, et al. Predictive value of GRACE risk scores for contrast-induced acute kidney injury in patients with ST-segment elevation myocardial infarction before undergoing primary percutaneous coronary intervention. Int Urol Nephrol. 2014;46(2):417-26.

47. Raposeiras-Roubin S, Aguiar-Souto P, Barreiro-Pardal C, Lopez OD, Elices TJ, Ocaranza SR, et al. GRACE risk score predicts contrast-induced nephropathy in patients with acute coronary syndrome and normal renal function. Angiology. 2013;64(1):31-9.

\section{Publisher's Note}

Springer Nature remains neutral with regard to jurisdictional claims in published maps and institutional affiliations.

Ready to submit your research? Choose BMC and benefit from:

- fast, convenient online submission

- thorough peer review by experienced researchers in your field

- rapid publication on acceptance

- support for research data, including large and complex data types

- gold Open Access which fosters wider collaboration and increased citations

- maximum visibility for your research: over $100 \mathrm{M}$ website views per year

At $\mathrm{BMC}$, research is always in progress.

Learn more biomedcentral.com/submissions 